GLOBAL JOURNAL OF

Community Psychology Practice

PROMOTING COMMUNITY PRACTICE FOR SOCIAL BENEFIT

Racismo ambiental e lutas por reconhecimento dos povos de floresta da Amazônia

Environmental racism and struggles for recognition of people in the Amazon forest

$\begin{array}{cccc}\text { Alessandro de Oliveira } & \text { Gustavo Martineli } & \text { Luís Guilherme Galeão } & \text { Bernardo Parodi } \\ \text { dos Santos } & \text { Massola } & \text { da Silva } & \text { Svartman }\end{array}$

Universidade de São Paulo

Palavras-chaves: Psicologia Comunitária, racismo ambiental, lutas por reconhecimento, Amazônia.

Keywords: Community Psychology, environmental racism, struggles for recognition, Amazon

Autor Biografias: Alessandro de Oliveira dos Santos: Professor do Departamento de Psicologia Social e do Trabalho do Instituto de Psicologia da Universidade de São Paulo onde é responsável pela área de Intercultura e Raça-Etnia. Professor visitante do Programa de Pós-Graduação em Psicologia da Universidade Federal de Rondônia, onde ministra a disciplina Pesquisa Psicossocial das Desigualdades na Amazônia. Tem experiência nos temas: relações interculturais e étnico-raciais; desigualdades; direitos humanos; religiosidade; comunidades tradicionais; conflitos socioambientais; turismo de base comunitária; planejamento em saúde. Gustavo Martineli Massola: Gustavo Martineli Massola é professor de Psicologia Ambiental do Instituto de Psicologia da Universidade de São Paulo e editor da revista Psicologia USP. Atualmente, pesquisa a relação entre enraizamento territorial e participação política, especialmente em comunidades tradicionais brasileiras e áreas de ocupação na cidade de São Paulo. Luís Guilherme Galeão-Silva: Professor Dr. do Departamento de Psicologia Social e do Trabalho da Universidade de São Paulo. Pesquisador nas áreas de Teoria Crítica da Sociedade, Psicologia Comunitária e Reconhecimento. Atualmente desenvolve pesquisa sobre conflitos, violência e memória em ocupações urbanas irregulares na cidade de São Paulo. Bernardo Parodi Svartman: Professor de Psicologia Social e Psicologia Comunitária no Instituto de Psicologia da USP. Atualmente investiga os temas da reificação e do desenraizamento, abordando também a forma pela qual os movimentos sociais da cidade de São Paulo desenvolvem estratégias de resistência a esses problemas psicossociais.

Citar: Oliveira dos Santos, A., Massola, G.M., Galeao da Silva, L.G., and Svartman, B.P. (2016). Racismo ambiental e lutas por reconhecimento dos povos de floresta da Amazônia. Global Journal of Community Psychology Practice, 7(1S), 1-20. Retrieved Day/Month/Year, from (http://www.gjcpp.org) 


\title{
Racismo ambiental e lutas por reconhecimento dos povos de floresta da Amazônia
}

\section{Resumo}

O racismo é uma ideologia, uma forma de opressão e de violência. A categoria analítica raça-etnia tem se mostrado um indicador eficaz nas ciências humanas para avaliar o acesso aos recursos naturais pelas populações, o direcionamento de políticas públicas e a alocação de resíduos. Na Amazônia, os recursos naturais e as externalidades negativas produzidas no ambiente têm sido distribuídos ao longo do tempo conforme a raça-etnia das populações que vivem na região, estabelecendo uma relação inexorável entre acesso ao patrimônio ambiental, problemas ecológicos e desigualdades sociais. Neste artigo, discutimos as lutas por reconhecimento de direitos territoriais e pelo manejo de princípios ativos (água, gás natural, pedras preciosas, entre outros) pelas populações tradicionais da Amazônia (indígenas, ribeirinhos, quilombolas), sob a perspectiva do racismo ambiental. Defendemos que a noção de racismo ambiental fornece uma linguagem compatível para compreender os conflitos socioambientais em curso na região, ao mesmo tempo em que se configura como um instrumento de advocacy capaz de influenciar na formulação de políticas públicas que efetivem e garantam os direitos dos povos que vivem na floresta.

\section{Environmental racism and struggles for recognition of people in the Amazon forest}

\begin{abstract}
Racism is an ideology, a form of oppression and violence. The analytical category race-ethnicity has been an effective indicator in the human sciences to evaluate access to natural resources by populations, the direction of public policies and the allocation of waste. In the Amazon, natural resources and the negative externalities produced in the environment have been distributed over time according to the race-ethnicity of people living in the region, establishing an inexorable link between access to environmental heritage, ecological problems and social inequalities. In this article, we discuss the struggles for recognition of territorial rights and the management of active ingredients (water, natural gas, precious stones, among others) by traditional Amazonian populations (indigenous, riveraine, maroon), from the perspective of environmental racism. We argue that the notion of environmental racism provides a consistent language to understand the socio-environmental conflicts underway in the region, while it is configured as an advocacy instrument capable of influencing the formulation of public policies that enforce and guarantee the rights of people living in the forest.
\end{abstract}




\section{Introdução}

A Psicologia como ciência dedica-se, entre outras possibilidades, à investigação dos condicionantes e da psicodinâmica do comportamento e à produção de métodos e técnicas de intervenção sobre grupos e indivíduos. Como profissão, surgiu atrelada à aplicação de testes voltados à detecção da anormalidade, da doença e do desvio e como modo de definir os parâmetros da normalidade, da saúde e da ordem. A invenção da norma via teste psicológico foi o ponto de partida para o estabelecimento da Psicologia como tecnologia de regulação do comportamento humano e da presença de psicólogos em diversos espaços da vida social (grupos, organizações, comunidades) onde se faz necessária a administração de pessoas (Rose, 2008).

Em termos gerais a Psicologia tem refletido amplamente uma expressão de epistemologias eurocêntricas, não só por sua origem, mas por seu papel nas justificativas da dominação como imposição e hegemonia de um único sistema produtivo e de interpretação de mundo - por meio da redução e naturalização dos problemas sociais como problemas individuais e particulares (Tassara \& Darmegian, 1996). Essa descontextualização, cultural, histórica e política, de suas teorias e pesquisas tem ajudado a endossar as desigualdades persistentes no planeta. No caso das populações autóctones ou tradicionais, aqui denominadas povos de floresta (indígenas, ribeirinhos, quilombolas), a universalidade abstrata do conhecimento psicológico tem cumprido um duplo papel de negarlhes, ao mesmo tempo, reconhecimento como sujeitos de conhecimento e de direitos. Desse modo, mesmo as políticas públicas ambientais mais críticas voltadas a essas populações têm se apresentado, notadamente, apenas como ferramentas de controle das externalidades negativas e das consequências produzidas pela razão hegemônica na exploração do ambiente.

Destarte, no bojo da própria Psicologia também têm se desenvolvido reflexões que problematizam seu papel na manutenção da ordem social vigente e que apontam para a possibilidade de que essa ciência e profissão contribuam para o enfrentamento da opressão na direção da emancipação de indivíduos e grupos. Um exemplo ocorre na própria formação do campo da Psicologia Comunitária na América Latina, cujos principais autores apontam a necessidade da produção de um conhecimento capaz de oferecer repostas e contribuições para lidar com os problemas da região e superar a alienação de seus povos. Montero (2005) e Martin-Baró (1986/2009) defendem que a longa história de escravidão e colonização deve ser tomada em consideração como o contexto social que alimentou e ainda influi sobre os mecanismos ideológicos e psicossociais que mantêm a opressão, o racismo e a hegemonia das epistemologias eurocêntricas na região.

Para Martin-Baró (1986/2009), por exemplo, uma Psicologia latinoamericana que resolvesse o problema de sua falta de relevância social seria aquela capaz de desenvolver um conhecimento que pudesse ajudar o processo de libertação dos diversos grupos oprimidos ao longo da história 
do continente. Essa Psicologia precisaria desenvolver a "recuperação da memória histórica" desses povos (p.195), algo que permitiria compreender como suas tradições e identidades formam um corpo de conhecimento fundamental no desenvolvimento de projetos efetivos de resistência política. 0 estudo e a valorização desse conhecimento seriam, por conseguinte, as características fundamentais dessa Psicologia enraizada na discussão dos problemas atuais e relevantes da América Latina.

Nesse sentido, a Psicologia

Comunitária apresenta necessariamente um núcleo histórico e regional ao lidar com problemas políticos contextualizados no espaço e no tempo. Ainda assim, apesar da diversidade que caracteriza o campo e que é determinada pelo seu próprio objeto de pesquisa e atuação, pode-se afirmar que um dos elementos que confere identidade à disciplina é o estabelecimento de parcerias com comunidades para promover processos de transformação social, visando muito mais atuar sobre as raízes e as estruturas sociais que produzem e perpetuam as injustiças do que simplesmente promover uma melhor distribuição de recursos existentes (Hale, 2014). 0 princípio ético da disciplina revela-se no objetivo explicitamente delimitado de se estudar os fatores psicossociais que apoiam e desenvolvem a autoorganização das comunidades, levando-as a identificar seus problemas e a construir suas estratégias de ação política. Nesse sentido, privilegia-se atuações que tenham efeitos não apenas imediatos, locais e restritos, mas que promovam melhorias de médio e longo prazo e que articulem a dimensão local com uma dimensão política mais ampla (tanto nacional como internacional). Objetivos que só podem ser alcançados quando as ações das comunidades são capazes de influenciar efetivamente as políticas públicas relacionadas aos problemas enfrentados (Wolff, 2013). Portanto, as relações entre organizações comunitárias, poder público e formulação/execução de políticas públicas configuram-se como um dos temas fundamentais do campo de atuação e pesquisa de uma Psicologia Comunitária de orientação crítica.

Na América Latina a Psicologia Comunitária surge no período das ditaduras civil-militares, conduzindo alguns psicólogos a discutir o contexto de negação dos direitos políticos e a estabelecer formas de pesquisa-ação ligadas aos movimentos sociais contestatórios do período (Lane, 1996; Sawaya, 1996; Montero, 2008). A partir da redemocratização dos países latinos na década de 1980, novos desafios surgem para a Psicologia Comunitária na região (Gohn, 2007). Se no período das ditaduras civil-militares, as políticas públicas não se apresentavam como um campo de atuação e pesquisa, visto que não estavam preocupadas efetivamente com a democratização do acesso a direitos sociais e políticos, o período posterior abriu espaço para novas relações entre a Psicologia Comunitária e as políticas públicas (Gonçalves \& Portugal, 2012). Desse modo, em vários países, ao longo da década de 1990, a Psicologia Comunitária foi convidada a refletir sobre como os movimentos sociais e comunidades organizadas podem participar do desenho e gestão de políticas públicas e lutar por seus 
direitos. A discussão sobre como participar do desenvolvimento, implantação e manutenção dessas políticas e quais fatores políticos e psicossociais podem favorecer essa participação torna-se um importante tema para o campo no século XXI (Inzunza \& Constanzo, 2009).

Entretanto, assim como em outros continentes, os estados latinoamericanos estão inseridos em um contexto de capitalismo globalizado e neoliberal. E é nesta arena que a Psicologia Comunitária na atualidade tem revelado a importância das lutas por reconhecimento das novas organizações comunitárias e movimentos sociais na direção de uma efetiva democratização das políticas públicas. Na atualidade, muitos desses conflitos estão localizados nas áreas rurais, e se expressam quando as comunidades tradicionais são ameaçadas com a perda de seus direitos territoriais e culturais em função da expansão de atividades econômicas ligadas ao grande mercado, como o turismo de massa, as atividades de mineração e o agronegócio, visando a exploração de recursos naturais desses territórios. As diversas formas pelas quais as comunidades tradicionais se organizam por meio de associações de moradores ou outras instâncias de representação e buscam enfrentar as injustiças e as ameaças a seu modo de vida, estratégias que envolvem a luta jurídica e política por reconhecimento de seus direitos territoriais, representam hoje uma importante dimensão psicossocial dos conflitos socioambientais presentes no território rural brasileiro e em especial no território amazônico.
Neste artigo teórico, produzido com base em revisão bibliográfica não sistemática da literatura de Psicologia, em sua especificidade de Psicologia Comunitária, e na análise de dados de fontes secundárias (pesquisas, reportagens de jornais, sites eletrônicos e revistas) sobre a Amazônia brasileira, discutimos as lutas por reconhecimento de direitos territoriais e pelo manejo de princípios ativos (como água, gás natural, pedras preciosas, entre outros) pelas populações tradicionais da Amazônia (indígenas, ribeirinhos, quilombolas), sob a perspectiva do racismo ambiental. Buscamos apresentar uma categorização dos conflitos socioambientais presentes na Amazônia, descritos tanto na literatura científica como em fontes secundárias, com o objetivo de estabelecer relações entre a noção de racismo ambiental e lutas por reconhecimento no campo da Psicologia Comunitária contemporânea. Defendemos que a noção de racismo ambiental fornece uma linguagem compatível para compreender os conflitos socioambientais em curso na região, ao mesmo tempo em que se configura como um instrumento de advocacy capaz de mobilizar as comunidades e de influenciar atores políticos institucionais na formulação de políticas públicas que efetivem e garantam os direitos dos povos que vivem na floresta.

\section{Raça e racismo}

Foi a partir da segunda metade do século XIX até a primeira Guerra Mundial que o termo "raça" ganhou destaque inserido em um projeto de diferenciação de povos, nações e culturas. Sua utilização neste período foi fruto de inúmeros fatores, entre os 
quais "a reação conservadora e antiigualitária a todo um conjunto de valores em torno da revolução francesa" e "o romantismo inspirado por autores, sobretudo alemães, com ênfase numa relação estreita entre nação, povo e cultura e a consolidação dos impérios coloniais" (Sansone, 2014, p.394). A relação entre este debate e as estratégias coloniais e escravistas nas Américas, as quais marcaram profundamente $o$ território aqui estudado, é de fundamental importância, especialmente se considerarmos, seguindo Quijano (2005, p.228), que "a ideia de raça, em seu sentido moderno, não tem história conhecida antes da América".

Após as tragédias da Segunda Guerra Mundial, assistiu-se a um esforço dos estudiosos, tanto na Psicologia com nas demais ciências humanas, para extinguir o termo raça, desautorizando seu uso como categoria analítica. Mas o início da Guerra Fria e dos processos de descolonização de países africanos e asiáticos somados à persistência do apartheid racial nos Estados Unidos e na África do Sul, mantiveram a atualidade do termo. Para Sansone (2014) foi-se criando uma polifonia de sentidos para o termo raça ao longo da história de modo que uma interpretação sociocultural foi substituindo outra de cunho mais físico-biológico, residindo neste uso "de alguma forma adaptável do termo raça, sua força e tenacidade ao longo do tempo" (p.397).

A raça, por conseguinte, permanece como um constructo sociológico, efeito de discursos, e que só faz sentido em um determinado contexto histórico, articulado a uma teoria. Trata-se de uma construção social que remete a discursos sobre as origens de um grupo com base em traços fisionômicos, transpostos para qualidades morais e intelectuais. Também se incorporam discursos sobre o lugar de origem do grupo em questão. Neste caso são discursos que remetem à etnia, ou seja, ao conjunto de indivíduos que histórica ou mitologicamente tem um ancestral, uma língua em comum, a mesma religião e cultura e compartilham o mesmo território (Guimarães, 2003).

No Brasil, utilizar apenas o termo etnia para designar os negros e indígenas parece insuficiente visto que eles não têm o mesmo ancestral comum e seus antepassados vieram de vários territórios que se misturaram no país configurando um verdadeiro "caldeirão étnico". Por outro lado, é o termo raça que melhor permite falar das desigualdades no país, evidenciando diferentes experiências de nascer, viver e morrer conforme o pertencimento racial da população. Por isso, neste artigo, sempre que possível, optou-se por utilizar os dois termos juntos, ou seja, étnico-racial.

Entendemos racismo aqui conforme define Sansone (2014), ou seja, tratase do uso "da raciologia (um credo popular ou popular-científico) por parte de um determinado grupo para discriminar outro grupo por sua diferença supostamente ancorada na biologia" (p.404). 0 autor chama atenção para as especificidades do racismo operante nos países de colonização portuguesa, o qual denomina de "versão católico-latina do racismo" (p.404), e cuja força está centrada "na combinação intensa de intimidade-proximidade e violência mais que no binômio segregaçãodiscriminação", (p.405) de maior 
prevalência nos países de colonização anglo-saxônica.

A manifestação social do racismo é a discriminação racial, ou seja, toda distinção, exclusão ou restrição baseada na raça-etnia e capaz de pôr em risco as liberdades fundamentais e os direitos em quaisquer esferas. A manifestação individual do racismo é o preconceito racial, ou seja, refere-se às percepções, atitudes e juízos preconcebidos a respeito de pessoas ou grupos de determinada raça-etnia e que não são facilmente modificáveis por apresentação de evidência contrária (Santos, 2012).

\section{Racismo ambiental $x$ justiça ambiental}

0 racismo é uma ideologia, uma forma de opressão e violência e o sustentáculo de um sistema de privilégios. A categoria analítica raçaetnia tem se mostrado um indicador eficaz nas ciências humanas para avaliar a distribuição de acesso aos recursos naturais pelas populações, o direcionamento de políticas públicas e a alocação de resíduos e lixo tóxico.

0 conceito de racismo ambiental surgiu no final da década de 1970 nos EUA a partir da mobilização da população negra do Condado de Warren na Carolina do Norte contra um depósito de resíduos tóxicos. Entre 1978 e 1982 constatou-se que três quartos desse tipo de aterro estavam localizados em locais habitados pela população negra, embora na região essa população representasse apenas 25\% dos habitantes (Pacheco, 2006).

Os ativistas de combate ao racismo ambiental nos EUA passaram então a desenvolver nas décadas seguintes estudos para mostrar que a raça era um bom indicador geográfico de carga ambiental. Por exemplo, as multas impostas por violações às normas ambientais em áreas habitadas pela população negra eram significativamente menores do que as aplicadas nos bairros habitados pela população branca (Alier, 2007). Nos EUA, o racismo ambiental revela conflitos a respeito da localização de incineradores e a disposição de dejetos tóxicos (nucleares).

Acreditamos que a noção de racismo ambiental pode ser ampliada para todas as minorias políticas étnicoraciais do planeta que lutam contra a distribuição desigual de acesso aos recursos naturais e a exposição a diferentes formas de risco ambiental nas áreas em que vivem. E que tal noção é capaz de estimular um movimento global dessas minorias políticas em direção à justiça ambiental, interpelando a economia a uma adequação ecológica e a sociedade à busca por uma maior igualdade social. Como diz Herculano (2008):

Os vazamentos e acidentes na indústria petrolífera e química, a morte de rios, lagos e baías, as doenças e mortes causadas pelo uso de agrotóxicos e outros poluentes, a expulsão das comunidades tradicionais pela destruição dos seus locais de vida e trabalho (...) configura uma situação de injustiça socioambiental, que vai além da problemática de localização de rejeitos químicos e de incineradores da experiência norte-americana. (Herculano, 2008, p.5)

0 que de fato é comum entre os EUA e o Brasil é que em ambos os países o 
contrário do racismo ambiental significa justiça ambiental, ou seja, um conjunto de princípios capaz de assegurar que nenhum grupo étnicoracial sofra o efeito desproporcional dos impactos ambientais negativos derivados das operações do capital, das políticas e programas públicos ou da sua ausência. Desse ponto de vista, racismo ambiental não se refere apenas às ações com intenção racista explícita, mas também àquelas que tenham efeito sobre os grupos étnicoraciais independente da intenção que lhes deu origem (Pacheco, 2006; Herculano, 2008).

Ora, sabemos que os conflitos socioambientais serão cada vez mais frequentes devido ao aumento da tensão pelo acesso aos recursos naturais e que a produção e circulação de mercadorias é o grande vetor de disputa pelo uso da natureza. Entretanto, essa mesma produção de mercadorias opera sobre uma base material que não se expande e está distribuída pelo planeta com maior concentração nos países do hemisfério sul (Ribeiro, 2010).

Por outro lado, nos conflitos socioambientais são possíveis diversos discursos de valoração. Há os discursos desenvolvimentistas com predomínio do crescimento econômico como remédio à pobreza. Há os discursos de compensação das externalidades negativas baseados em análises de custo-benefício (ecoeficiência). E há o discurso que clama aos direitos humanos, aos direitos territoriais e à sacralidade dos espaços de vida. Todos são discursos socialmente válidos. Mas, quem tem o poder de simplificar e sacrificar interesses e valores impondo um único discurso de valoração, como tem ocorrido com o discurso econômico? (Alier, 2007).

Na Amazônia, os recursos naturais e as externalidades negativas produzidas no ambiente têm sido distribuídos ao longo do tempo conforme a raça-etnia das populações que vivem na região, estabelecendo uma relação inexorável entre acesso ao patrimônio ambiental, problemas ecológicos e desigualdades. A noção de racismo ambiental pode auxiliar lideranças comunitárias, ativistas e pesquisadores da Amazônia a sair do embate entre preservacionismo (no qual as atividades antrópicas são responsabilizadas pela degradação dos sistemas ecológicos) versus conservacionismo (no qual as atividades antrópicas são consideradas fundamentais para conservação dos sistemas ecológicos), em direção a um debate mais denso sobre justiça ambiental. Pois o que está em jogo é como defender os direitos dos povos de floresta ameaçados atualmente por grandes obras de infraestrutura e propostas de reformas dos marcos regulatórios que os protegem. São povos que, apesar do pouco espaço ambiental que ocupam, têm gerenciado sistemas agrícolas e agroflorestais sustentáveis e cuja sobrevivência está ameaçada por indústrias poluidoras, grandes complexos energéticos e monoculturas destrutivas. Esses povos têm melhores possibilidades de defender seus interesses no campo do não-econômico.

Ao enfatizar o racismo ambiental como instrumento de advocacy nos aliamos ao movimento global por justiça ambiental que prioriza a incomensurabilidade de valores na relação ser humano e ambiente. Por exemplo, se uma mineradora é 
responsável pela contaminação de uma comunidade quilombola com chumbo ela pode aplicar o princípio do poluidor pagador e compensar financeiramente o dano provocado. Mas, o que significa infligir tal golpe à dignidade humana de um grupo ao lançar mão de uma agressão ambiental configurada por meio da discriminação racial? Pagar uma multa nesse caso não dá o direito de repetir tal comportamento. Isso porque não existe uma compensação real, visto que o dinheiro e a dignidade humana não são equiparáveis, ou pelo menos, não deveriam ser.

\section{Conflitos socioambientais como expressão de racismo ambiental na} Amazônia

A Amazônia é a maior fonte de biomassa renovável e a mais importante bacia de água doce do planeta, além de possuir incalculáveis recursos agroflorestais, icitiofaunísticos e biotecnológicos (Lira, Costa, Fraxe, \& Witkoski, 2014).

O histórico de ocupação da Amazônia brasileira desde o período colonial está ligado aos conflitos étnicoraciais. Inicialmente, entre portugueses e indígenas para imposição do mercantilismo português com base na mão de obra escrava ameríndia. Em seguida, durante a segunda metade do século XIX, por conta da economia gumífera de exploração do látex, que atraiu migrantes de várias regiões do país, sobretudo do Nordeste, cuja primazia na ocupação de terras desencadeou inúmeros conflitos com os povos de floresta. Na segunda metade do século XX, por sua vez, a Amazônia passou a receber grandes projetos intervencionistas da ditadura civilmilitar brasileira sem nenhum respeito pelos povos de floresta ou consideração pela vocação da região. Nesse período o governo patrocinou a abertura de rodovias, projetos de exploração mineral e de instalação de fazendas agropecuárias e monoculturas agrícolas. Tal falta de respeito e consideração, reflexo de uma história de ocupação ligada à escravidão e subjugação dos povos de floresta, fizeram da região um palco de conflitos socioambientais e de agressões a seus habitantes. Em todos esses momentos históricos citados é possível notar como a exploração econômica e a dominação política na região esteve e ainda está atravessada pela dimensão étnico-racial: a classe dominante local é herdeira direta dos processos de colonização, e muitas vezes as políticas públicas foram executadas de forma a atender seus interesses e facilitar sua perpetuação no poder. Os grupos explorados que sofrem os impactos dessa dominação estão representados nas diversas etnias indígenas autóctones, nas comunidades quilombolas que resistiram à escravidão e nas comunidades ribeirinhas formadas basicamente por trabalhadores e pequenos agricultores que se recusaram a participar do agronegócio como mão-de-obra contratada pelos grandes proprietários de terras. Apesar das enormes diferenças entre esses grupos, pode-se dizer que desenvolveram uma cultura comunitária de resistência ligada à manutenção de suas tradições e de um específico manejo dos recursos naturais no território. Mais recentemente, com a intensa disputa pelo território e pelo acesso aos recursos naturais, novamente os conflitos étnico-raciais estão em pauta, dessa vez com a retomada de 
laços étnicos e a auto-atribuição de identidades protagonizadas pelos povos de floresta.

Ora, desde o período colonial a Amazônia é tomada como fonte de matérias-primas. E para melhor vendê-la e explorá-la tem sido apresentada como habitada por populações não brancas devotas do extrativismo dos recursos naturais. Essa vontade de manter os povos de floresta regredidos ao extrativismo revela mais os anseios da indústria farmacêutica e biotecnológica internacional, do que propriamente a capacidade desses povos de se desenvolver sem incentivo do mercado ou assistência do poder público. Como diz Souza (2002):

o certo é que, se o extrativismo na Amazônia não está morto, deve ser definitivamente erradicado por qualquer plano que respeite o processo histórico e a vontade regional. Mesmo porque a Amazônia não deve ser reserva de nada, nem celeiro, nem estoque genético ou espaço do rústico para deleite dos turistas pósindustriais. (Souza, 2002, p.35)

Atualmente, além da pressão pelo extrativismo a Amazônia brasileira figura como região de enorme potencial hidrelétrico e para expansão do agronegócio e da mineração. Em seu interior faltam empregos, oportunidades de renda, serviços e equipamentos públicos, expressando um desequilíbrio entre o meio rural e urbano, o campo e a cidade, no acesso às políticas e serviços, semelhante ao de outras regiões brasileiras. Em termos gerais, trata-se de uma região com "moderada" ocupação humana e "escassa" atividade econômica. Embora seja preciso levar em conta que em função de sua enorme extensão territorial e seu passado recente, tenha uma ocupação extremamente diferenciada internamente (Witkoski, Fraxe, \& Cavalcante, 2014).

É no interior da Amazônia que vemos a luta dos povos indígenas, quilombolas e ribeirinhos para manterem suas terras frente à pressão pela exploração mineral e/ou instalação de hidrelétricas. A ironia é que foram esses povos, ao manterem um manejo adequado do ambiente, que permitiram a conservação da floresta, de modo que hoje muitos commodities e princípios ativos (água, gás natural, pedras preciosas, entre outros) se encontram em seus territórios.

Por isso, defendemos que o racismo ambiental é capaz de fornecer uma linguagem compatível para compreender os conflitos socioambientais no interior da Amazônia. Isso porque os mecanismos e processos sociais postos em marcha pelo racismo ambiental, ao naturalizar as hierarquias sociais, inferiorizam os grupos étnico-raciais ao ponto de tomar como espaços físicos vazios os territórios ocupados por esses grupos. Como diz Bullard (2004):

0 racismo é um potente fator de distribuição seletiva das pessoas no seu ambiente físico: influencia o uso do solo, os padrões de habitação e o desenvolvimento de infraestrutura. (Bullard, 2004, p.57) 
Os conflitos socioambientais podem ser categorizados de várias maneiras, tomando como critério desde a fonte ou origem do ativo em disputa, como terras, minério ou a cultura de um povo (no caso de iniciativas de conversão religiosa, por exemplo), até o tipo de dano causado ao grupo afetado, que pode envolver sua saúde, sua identidade étnico-racial ou mesmo sua sobrevivência. Uma percepção difundida sobre os conflitos socioambientais na Amazônia toma como critério de categorização a atividade econômica geradora da disputa, e indica que, atualmente, a região apresenta conflitos em torno de três grandes eixos econômicos: geração de energia hidrelétrica, agronegócio e mineração.

Os grandes projetos de construção de usinas para a geração de energia hidrelétrica ganharam destaque em todo o mundo ao obrigarem o deslocamento de grandes contingentes populacionais e mudarem os ciclos dos rios em suas fases de enchente, cheia, vazante e seca. No estado de Rondônia, por exemplo, as usinas de Jirau e Santo Antônio produziram a maior cheia da história em 2014 destruindo mais de 50 comunidades ao longo do Rio Madeira - o que tem levado as populações tradicionais dos Estados do Acre, Pará e Rondônia a se organizarem para resistir a tais projetos frente a uma diretriz política de governo que tem transformado os rios da Amazônia em máquinas de produção de energia.

No que se refere ao agronegócio, por sua vez, é conhecido o fato de que parte significativa da perda de cobertura vegetal da Amazônia devese nas últimas décadas à expansão da pecuária e de atividades como a sojicultura. Ademais, há muitos anos, a mineração praticada em escala industrial ou artesanal vem sendo acusada pela degradação de imensas áreas no interior da floresta e pelo comprometimento do modo de vida de populações tradicionais. Uma decisão recente da Justiça Federal em 2014, por exemplo, suspendeu 500 processos de pedido de autorização para exploração mineral em terras indígenas no Estado do Amapá. 0 pedido do Ministério Público Federal, acatado pela Justiça, argumentava que não havia legislação que regulasse esta atividade. Mesmo assim, o Departamento Nacional de Produção Mineral manteve a análise dos pedidos, agora suspensa, numa ação que afrontava diretamente o sistema jurídico nacional.

Se esta categorização assim definida pode ser útil para a compreensão de muitos conflitos na Amazônia, não deixa de ser parcial. A lista dos conflitos socioambientais envolvendo de um lado os investimentos econômicos ou do poder público e de outro os povos de floresta do interior da Amazônia é imensa e variada. Como exemplo, relacionamos a seguir alguns conflitos nos Estados do Acre, Amazonas e Pará: falta de atendimento à saúde das populações tradicionais; tráfico de cocaína alterando o modo de vida indígena; grilagem e falta de regularização fundiária de territórios de populações tradicionais; projetos turísticos de massa e de pesca predatória que afetam indígenas e ribeirinhos; implantação de gasodutos, obrigando ao deslocamento de populações tradicionais; biopirataria (Porto, Pacheco, \& Leroy, 2013). 
Nota-se que o cerne dos conflitos reside tipicamente na necessidade de expansão do grande capital, que precisa fazer uso dos recursos encontrados em áreas protegidas ou habitadas por populações tradicionais, as quais se colocam como obstáculos a esta expansão. Paralelamente, as necessidades geopolíticas do governo brasileiro, vinculadas ao grande capital, implicam investimentos massivos que levam à alteração no modo de vida de muitas populações. Neste cenário, a Amazônia se oferece como fonte de recursos para a produção de mercadorias que, distribuídas no mercado global, torna a utilização econômica dos recursos naturais provenientes da região, hoje, um fenômeno de caráter transnacional. Em outras palavras, não se pode identificar e compreender os conflitos socioambientais na Amazônia como um fenômeno meramente local.

Os conflitos socioambientais têm hoje caráter global, especialmente em um momento no qual a globalização, tomada como a difusão para todo o mundo da cosmovisão e das instituições da civilização ocidental de base eurocêntrica, impõe-se rapidamente sobre as alternativas políticas locais existentes. Esta globalização hegemônica, que apresenta uma visão de mundo particular como tendo validade universal e procura naturalizá-la, estabelece distinções hierárquicas entre povos ou países centrais aqueles que estão na origem deste processo de expansão global - e povos ou países periféricos - que acolhem esta expansão ao custo do desaparecimento das alternativas culturais locais representadas por populações tradicionais cuja história e cuja cosmovisão é aniquilada no contato com as instituições culturais dominantes. Processo que Boaventura de Sousa Santos chama de epistemicídio, ou a "morte de um conhecimento local perpetrada por uma ciência alienígena" (Sousa Santos, 2005, p. 22) e que configura tais conflitos socioambientais como marcadamente centrados em disputas geopolíticas envolvendo culturas centrais e culturas periféricas.

O caráter étnico-racial dos conflitos socioambientais não é fortuito, pode ser considerado uma consequência direta de sua configuração geopolítica em um mundo globalizado, e tem sido enfrentado em nível global, entre outras formas, por tentativas de criação de regras internacionais para proteger os povos não centrais frente a esta ação hegemônica. A expressão socioambiental deste tipo de desigualdade foi combatida, por exemplo, pela Convenção 169 da OIT (Organização Internacional do Trabalho), que protege o território das populações indígenas, e pela Convenção da Basileia, que proíbe a exportação de resíduos tóxicos para África.

Este fenômeno que opera em nível global opera também em nível local, com os territórios ocupados por culturas e povos tradicionais, cuja forma de produção econômica distingue-se daquela que rege a expansão do grande capital, sendo desigualmente atingidos por atividades econômicas predatórias ou pela desapropriação direta, com a expulsão de seus habitantes. Não se trata neste caso de denunciar a ausência de compensação pelas externalidades ambientais expropriadas desses povos, mas de apontar que há um marcado 
componente étnico-racial na própria ação de expropriação. Nos estudos clássicos sobre o racismo ambiental, foi-se constituindo um forte argumento, calcado em significativas evidências empíricas, que conclui pela existência de um deslocamento geográfico tanto das fontes de recursos, buscadas cada vez mais nos territórios ocupados por grupos étnico-raciais definidos, quanto das áreas de descarte de resíduos. 0 reconhecimento da existência do racismo ambiental em outros lugares pode muito bem, por outro lado, tornar mais complexa a descrição do fenômeno. No caso da Amazônia, o discurso que explicita o racismo ambiental o faz sob a bandeira dos direitos territoriais indígenas, quilombolas e das populações ribeirinhas.

A ganância e o preconceito ingredientes essenciais ao racismo ambiental - tratam o território como se ele fosse deserto de vidas. Como se terra, água e floresta, os três habitats que delimitam os espaços de vida e trabalho das populações tradicionais na Amazônia (Witkoski, 2010), não fossem ocupados por seres humanos que ali nasceram e cujos ascendentes ali constituíram suas moradias, seus meios de sobrevivência, suas tradições, seus laços de parentesco e de amizade. Em alguns casos, essa expropriação se dá de forma relativamente pacífica. A falácia do desenvolvimento e do progresso, aliada ao oferecimento de empregos temporários, transforma o assalto em uma forma de suicídio: as próprias populações tradicionais são convencidas a colaborar no desmatamento, na destruição da floresta, até mesmo no garimpo que envenenará suas águas. Cumprida essa última parte de sua "função social" na ótica do capital, essas "subraças" podem ser "dispensadas", o que no caso é sinônimo de expulsão sumária. Quando resistem, os métodos mudam. E irão desde o uso da violência e dos "jagunços", à compra de registros e autoridades, numa usurpação de direitos que é um verdadeiro escárnio à concepção de justiça (Porto, Pacheco, \& Leroy, 2013).

\section{Lutas por reconhecimento dos povos de floresta}

O manejo do território e dos recursos naturais é o principal meio de manutenção e reprodução material e simbólica dos povos de floresta. A negação disso constitui uma afronta à sua capacidade de sobrevivência e uma desconsideração profunda de sua condição como sujeitos de conhecimento e de direitos, visto que a biodiversidade e demais riquezas da Amazônia derivam diretamente do manejo secular desses povos sobre a terra, as águas e a floresta (Lira, Costa, Fraxe, \& Witkoski, 2014).

Tais povos não são incapazes de se defender, pelo contrário, com base em uma perspectiva que assume a identidade étnico-racial como síntese de forças políticas e simbólicas que se produzem em uma determinada territorialidade (Miguez, Fraxe, Souza, \& Witkoski, 2014), eles têm procurado reverter a contradição entre identidade dominante e identidade oprimida, por meio da afirmação de sua diferença e da construção de uma identidade como projeto político (Castel, 1997), retomando antigos laços étnicos e se auto-atribuindo denominações como quilombolas ou ribeirinhos, por exemplo.

A identidade hegemônica é constituída a partir de ideologias 
como o racismo, que justificam a concentração de recursos materiais e simbólicos em determinado grupo social identificado a atributos valorizados abstratamente. Ou seja, atributos como cor da pele ou origem ocidental passam a ser apresentados como pele branca superior a pele escura e origem ocidental superior a origem indígena. Esse processo só se completa na instituição de uma identidade oprimida, objeto de preconceito e estereotipia. A construção de uma identidade política como reação a isso considera a singularidade forçada pela desigualdade como fator de reunião de forças contra-hegemônicas.

É somente a partir daí que tem início uma luta por reconhecimento de direitos para além de uma igualdade abstrata, ou seja, considerando a noção de equidade. Assim, a noção de reconhecimento articula a diferença e a igualdade de modos distintos conforme o contexto político. Vale dizer: afirma a justiça da diferença onde a igualdade abstrata sustenta a injustiça e afirma a justiça da igualdade abstrata onde a diferença sustenta a injustiça (Sousa Santos, 2004, 2007). Por exemplo, a igualdade abstrata de todos poderem comprar terras na Amazônia é injusta com povos cuja posse da terra não está representada no mercado ou no estado ocidental. Os indígenas têm um direito à diferença, às terras demarcadas, para além do mercado capitalista da compra e venda de terras, bem como têm uma posse ancestral da terra que não é representada nos cartórios imobiliários dos estados brasileiros. Por outro lado, a diferença da posse de meios de coação e agressão por parte de grileiros de terras na Amazônia exige a manutenção da igualdade dos direitos humanos à vida com vistas à proteção dos indígenas.

Desse modo, a luta por reconhecimento dos povos de floresta da Amazônia revela uma importante dimensão psicossocial e indica a importância desse assunto no campo da psicologia comunitária contemporânea: ao mesmo tempo em que um grupo amplia sua visibilidade e inserção política na totalidade social, o faz à medida em que elabora e se apropria de sua específica história de resistência à dominação política e exploração econômica. As pesquisas nesse campo podem ajudar a compreender os diversos processos psicossociais e políticos nos quais a elaboração da história de dominação e de desigualdade como ponto de apoio da identidade não termine por isolar o grupo ou construir formas xenófobas de pertencimento, mas pelo contrário, permita trabalhar a dialética entre particular e universal conduzindo a uma inserção social que respeite a singularidade cultural e, ao mesmo tempo, garanta a universalidade dos direitos do ponto de vista de grupos historicamente oprimidos. Ou seja, a partir do momento em que esses povos passam a caminhar na direção da conquista ou manutenção de seus direitos sociais e políticos, obrigam a esfera pública a lidar com uma forma concreta e particular de afirmação da universalidade dos direitos humanos.

A essa dialética, repleta de contradições, soma-se a possibilidade de que os projetos éticos, políticos e espirituais desses grupos sejam respeitados e valorizados como possibilidades de redefinição das formas violentas pelas quais o grande 
mercado tem assimilado territórios ocupados tradicionalmente e ancestralmente, configurando-se como um importante elemento constituinte dos novos processos de participação e de co-gestão de políticas de públicas.

\section{Considerações finais}

Neste artigo expusemos dois fatos fundamentais a respeito dos povos de floresta da Amazônia. Primeiramente, as principais transformações sociais e econômicas vividas por esses povos delineiam-se a partir de suas tentativas de resistência aos processos de dominação presentes na ocupação de seu território e à progressiva assimilação predatória dos recursos naturais à economiapolítica nacional e internacional. Em segundo lugar, as políticas públicas formuladas, com raras exceções, não consideraram o processo histórico e os direitos desses povos, expressando basicamente uma contradição entre "proteger" ou "deixar matar" essas populações.

Esses dois fatos são complementares e determinam o campo de conflitos no qual os povos de floresta elaboram suas lutas por reconhecimento e contra o racismo ambiental. Esses dois processos são opressores na medida em que não exprimem o conjunto de forças vivas do território e impedem os povos de floresta de influir sobre as decisões quanto ao uso dos recursos naturais (Miguez, Fraxe, Souza, \& Witkoski, 2014).

A noção de racismo ambiental pode ser um valioso instrumento de advocacy na luta por reconhecimento dos povos da floresta, ao permitir um confronto direto com as propostas desenvolvimentistas ou de defesa de compensação ambiental como forma de retribuição justa pelos danos causados às populações tradicionais. Em contraposição a tais propostas, a noção de racismo ambiental aponta para a incomensurabilidade de valores presentes na relação entre ser humano e ambiente e, por conseguinte, à impossibilidade éticopolítica de que benefícios econômicos possam equivaler sob qualquer forma a dignidade e a vida humana. Os valores implícitos às propostas desenvolvimentistas ou compensatórias vêm ditando as interpretações sobre os conflitos socioambientais na Amazônia, articulando-se a políticas públicas que desconsideram as vidas humanas que ali desenvolveram sua história pessoal e coletiva e, muitas vezes, promovendo a cooptação das próprias comunidades locais em ações que degradam o local do qual depende sua existência digna. Por outro lado, a noção de racismo ambiental fornece uma linguagem que permite articular politicamente as populações locais da Amazônia, em uma ação de advocacy de caráter interno a essas próprias populações, capaz de fomentar seu protagonismo político, e de forma coerente com a história recente da Psicologia Comunitária latino-americana. Isso porque, permite expressar com precisão uma concepção de justiça que toma em consideração as desigualdades sociais na elaboração de políticas públicas, vinculando diferenças materiais e igualdade formal de direitos - o que, segundo nos parece, constitui o sentido mais profundo da ideia de reconhecimento.

Recentemente, a Psicologia Comunitária na América Latina começou a investigar as relações entre formas de participação popular 
e definição de políticas públicas. Além disso, a Psicologia Comunitária também começou a tematizar em suas pesquisas e programas de formação como as lutas de organizações comunitárias se relacionam à discussão de questões ambientais, como a preservação de certos territórios e o uso sustentável de recursos naturais (Watkins \& Ciofalo, 2011). No caso brasileiro, a história da Psicologia Comunitária no país (Lane, 1996; Gonçalves \& Portugal, 2012), revela que a disciplina dedicou-se inicialmente, sobretudo, à investigação de problemas urbanos, problemas surgidos em torno das lutas de um conjunto de movimentos sociais pelo direito à cidade e pela redemocratização política, fazendo com que a atenção dada às comunidades rurais e aos povos da floresta tenha sido menor se comparada com a produção de pesquisas em torno das questões urbanas. No entanto, a expansão do agronegócio e a integração de territórios ocupados por comunidades tradicionais ao mercado global, aliado a políticas de estado com grande impacto ambiental e social em áreas rurais a partir da década de noventa, tornou a temática cada vez mais relevante para esta área de conhecimento. Esta nova conjuntura política da relação entre espaço rural, comunidades tradicionais, mercado global e Estado, assim como o surgimento de novos movimentos sociais (principalmente articulados por meio de associações de moradores dessas comunidades tradicionais que lutam contra esses processos de dominação), colocam novos desafios para a Psicologia Comunitária, que começam agora a ser enfrentados, no sentido de fortalecer o Brasil e as comunidades tradicionais que aqui vivem em direção a um desenvolvimento humano e social que permita superar as desigualdades persistentes no país. Defendemos neste artigo que um dos desafios atuais encontra-se em incentivar a participação dessas comunidades tradicionais na construção de políticas de garantia de direitos sociais e territoriais, ao mesmo tempo que tais políticas reconheçam o direito à diferença e de proteção frente às ameaças ligadas aos interesses de exploração econômica da região. Para que a Psicologia Comunitária possa oferecer contribuições faz-se necessário que os psicólogos investiguem com mais profundidade: a maneira pela qual as comunidades incentivam a participação de seus membros em lutas políticas para defesa do território e de sua cultura frente às ameaças advindas do grande mercado; como promovem um diálogo entre suas tradições e o corpo de conhecimento ligado ao direito e à participação política institucional; e como desenvolveram e mantêm formas de manejo dos recursos naturais que preservam o território que habitam (vale dizer através de formas completamente distintas de manejo em relação à lógica do agronegócio). A pesquisa deste conjunto de temas é essencial para o desenvolvimento do conhecimento e atuação no campo da Psicologia Comunitária no contexto político atual e no que se refere, em particular, ao território da Amazônia, apontando grandes dilemas sobre os quais a Psicologia Comunitária deve se debruçar, como a luta pelos direitos das comunidades tradicionais pelo uso dos recursos naturais e o 
papel da Amazonia, como fonte de recursos, no mundo contemporâneo.

0 desafio que se apresenta nesse contexto é o de se produzir uma Psicologia que seja fruto e legitimamente interessada no bem estar da população como um todo, e não apenas em uma pequena parcela que concentra os recursos e representa os colonizadores tanto por identificação como por ações que transferem riquezas da população para a acumulação internacional. É necessário estar com a comunidade em posição de igualdade com os saberes locais e estar preocupado com o fortalecimento do protagonismo local e com as lutas emancipatórias propostas por seus atores e não por uma escala de valores aparentada a um universalismo abstrato. Este processo não pode ser realizado sem um diálogo que respeite a cultura e as tradições desses grupos.

Ao adentrar nessas comunidades o psicólogo comunitário deve valorizar esses conhecimentos, na tentativa de constituir um campo de composição entre os saberes populares e especializados, capaz de integrar leituras de mundo, da realidade e dos problemas vivenciados nas comunidades (Santos, 2016). É sob essa perspectiva que sua atuação se torna possível diante do racismo ambiental: promovendo a articulação entre indivíduos e organizações do poder público e da sociedade civil. Tal atuação deve propiciar um ambiente formador para todos os envolvidos, que permita a troca de experiências, facilite que as ações sejam elaboradas a partir da compreensão da realidade local e mostre os ganhos para os municípios e comunidades de se investir em ações de identificação e combate ao racismo ambiental.

Por conseguinte, uma Psicologia Comunitária engajada na emancipação psicossocial de indivíduos e grupos oprimidos precisa marcar uma diferença radical na epistemologia que represente a superação da justificativa da opressão por meio da ciência. Uma nova ciência deve abarcar as epistemologias do Sul, ou seja, ir ao encontro de formas de resistência e conhecimento que se oponham à dominação presente nas periferias do planeta. Somente deste modo, o reconhecimento da epistemologia e da subjetividade dos povos de floresta pode se configurar como uma forma de justiça ambiental.

\section{Referências bibliográficas}

Alier, J. M. (2007). O ecologismo dos pobres: conflitos ambientais e linguagens de valoração. São Paulo: Contexto.

Bullard, R. (2004). Enfrentando o racismo ambiental no seculo XXI. In: Ascselrad, H, Herculano, S. e Pádua, J. A. Justiça ambiental e Cidadania (pp. 57-68). Rio de Janeiro: RelumeDumará.

Castel, R. (1997). A Dinâmica do Processo de Marginalização: da vulnerabilidade a desfiliação. Caderno CRH, 26/27, 19-40.

Gohn, M. (2007). Teoria dos movimentos sociais: paradigmas clássicos e contemporâneos. São Paulo: Loyola. 
Gonçalves, M. A., \& Portugal, F. T. (2012). Alguns apontamentos sobre a trajetória da Psicologia social comunitária no Brasil. Psicologia: Ciência e Profissão, 32(spe), 138-153.

Guimarães, A. S. A. (2003). Como trabalhar com "raça" em sociologia. Educação e Pesquisa, 29, 93-107.

Hale, M. R. (2014). Community Organizing: for Resource Provision or Transformation? A review of the Literature. Global Journal of Community Psychology Practice, 5(1), 1-9.

Herculano, S. (2008). 0 clamor por justiça ambiental e contra o racismo ambiental. Revista de Gestão Integrada em Saúde do Trabalho e Meio Ambiente, 3(1),1-20.

Inzunza, J. F., \& Constanzo, A. Z. (2009). Psicología comunitária y políticas sociales en Chile. Psicologia \& Sociedade, 21(2): 275-282.

Lane, S. (1996). Histórico e fundamentos da Psicologia Comunitária no Brasil. In Campos, Regina Helena de Freitas. (org.) Psicologia Social Comunitária. Da solidariedade a autonomia (pp. 27-32). Petrópolis: Vozes.
Lira, S. H., Costa, D. C., Fraxe, T. J. P, \& Witkoski, A. C. (2014). Sustentabilidade e territorialidade: dilemas, desafios e possibilidades de vida para as populações rurais amazônicas. In: Witkoski, A. C.; Fraxe, T. J. P. e Cavalcante, K. V. (Orgs). Território e territorialidade na Amazônia: formas de sociabilidade e participação política (pp. 5586). Manaus: Editora Valer.

Martin-Baró, I. (2009). Para uma Psicologia da Libertação. In: GUZZO, R.S.L, JÚNIOR, F.L. (orgs.). Psicologia social para América Latina: o resgate da psicologia da libertação. Campinas, SP: Alínea. (Trabalho original publicado em 1986)

Miguez, S. M., Fraxe, T. J. P., Souza, D. S. R., \& Witkoski, A. C. (2014). Os movimentos sociais e a construção da cidadania amazônica no âmbito das políticas territoriais. In: Witkoski, A. C.; Fraxe, T. J. P., \& Cavalcante, K. V. (Orgs). Território e territorialidade na Amazônia: formas de sociabilidade e participação política (pp. 197-224). Manaus: Editora Valer.

Montero, M. (2005). Introduccion a la psicologia comunitária. Buenos Aires: Paidos.

Montero, M. (2008). An insider's look at the development and current state of community psychology in Latin America. Journal of Community Psychology, 36 (5), 661-679. 
Pacheco, T. (2006). Desigualdade, injustiça ambiental e racismo. I Seminário Cearense contra o Racismo Ambiental, Fortaleza.

Porto, M. F., Pacheco, T., Leroy, J. P. (2013). Injustiça Ambiental e Saúde no Brasil. O mapa de conflitos. Rio de Janeiro: FIOCRUZ.

Quijano, A. (2005). Colonialidade do poder, eurocentrismo e América Latina. In E. Lander (Org.). $A$ colonialidade do saber. Eurocentrismo e ciências sociais, perspectivas latino-americanas (pp. 227-278). São Paulo: CLACSO.

Ribeiro, W. C. (2010). Geografia política e gestão internacional dos recursos naturais. Estudos Avançados, 23, 69-80.

Rose, N. (2008). Psicologia como uma ciência social. Psicologia \& Sociedade; 20(2),155-164.

Sansone, L. (2014). Raça. In: Lívio Sansone e Claúdio Alves Furtado. (Orgs). Dicionário crítico das ciências sociais dos países de fala oficial portuguesa. (pp. 393-411). Salvador: Edufba.

Santos, A. O. (2012). Superar o racismo e promover a saúde da população negra. In: Paiva, V.; Ayres, J. R. M. e Buchalla, C. M. (Orgs.). Vulnerabilidade e Direitos Humanos. Prevenção e Promoção da Saúde. Da doença à Cidadania. (pp. 145-163). Curitiba: Juruá Editora.
Santos, A. O. (2016). Atuação do(a) psicólogo(a) social na proteção de direitos de crianças e adolescentes de comunidades anfitriãs do turismo na Amazônia. In: Calegare, M. G. A. e Higuchi, M. I. G. (Orgs.). Nos interiores da Amazônia: leituras psicossociais. (pp. 229-248). Curitiba: Editora CRV.

Sawaia, B. (1996). Comunidade: a apropriação científica de um conceito tão antigo quanto a humanidade. In: Campos, R. H. F. (org.). Psicologia Social Comunitária - da solidariedade à autonomia. (pp. 35-53). Rio de Janeiro: editora Vozes.

Sousa Santos, B. (2004). Reconhecer para Libertar: os caminhos do cosmopolitismo multicultural. Porto: Afrontamento. . (2005). Semear outras soluções. Os caminhos da biodiversidade e dos conhecimentos rivais. Rio de Janeiro, Civilização Brasileira. (2007). Renovar a teoria crítica para reinventar a emancipação social. São Paulo: Boitempo.

Souza, M. (2002). Amazônia e modernidade. Estudos Avançados; 16(45), 31-36.

Tassara, E. T. 0.; Darmegian, S. (1996). Para um novo humanismo: contribuições da Psicologia Social. Estudos Avançados; 10(28), 291-316. 
Watkins, M.; Ciofalo, N. (2011).

Creating and sharing critical community psychology curriculum for the 21st century: nainvitation. Global Journal of Community Psychology Practice, 2(2), 9-18.

Witkoski, A. C. (2010). Terras, florestas e águas de trabalho: os camponeses amazônicos e as formas de uso de seus recursos naturais. São Paulo: Annablume.

Witkoski, A. C.; Fraxe, T. J. P., \& Cavalcante, K. V. (2014). Introdução. In: Witkoski, A. C.; Fraxe, T. J. P. e Cavalcante, K. V. (Orgs). Território e territorialidade na Amazônia: formas de sociabilidade e participação política. (pp. 1117). Manaus: Editora Valer.

Wolff, T. A. (2013). Community

Psychologist's involvement in policy change at the community level : Three stories from a practioner. Global Journal of Community Psychology Practice, 4(2), 2-12. 